\title{
The Routledge companion to political journalism.
}

\author{
MORRISON, J., BIRKS, J. and BERRY, M.
}




\section{THE ROUTLEDGE COMPANION TO POLITICAL JOURNALISM}

Edited by James Morrison, Jen Birks

and Mike Berry

First published 2022

ISBN: 978-0-367-24822-2 (hbk)

ISBN: 978-0-429-28457-1 (ebk)

Chapter 28

MEDIA EFFECTS ON PERCEPTIONS OF SOCIETAL PROBLEMS: BELIEF FORMATION IN FRAGMENTED MEDIA ENVIRONMENTS

Adam Shehata

(CC-BY-NC-ND 4.0)

DOI: $10.4324 / 9780429284571-28$

The funder for this chapter is University of Gothenburg 


\title{
28 \\ MEDIA EFFECTS ON PERCEPTIONS OF SOCIETAL PROBLEMS: BELIEF FORMATION IN FRAGMENTED MEDIA ENVIRONMENTS
}

\author{
Adam Shehata
}

The news media are typically considered vital for understanding public opinion formation in democratic societies. Through various media, people learn about issues, events and actors beyond their personal and everyday experiences - with potentially significant implications for citizens' understanding of politics, attitudes and voting behavior.

Dating back to the early writings of American journalist Walter Lippmann (1922), the news media are seen as particularly influential in shaping the pictures in our heads of the world outside. As such, how media help people define social reality has been a key question in media effects research, especially since the cognitive turn in social science during the 1970s (Perse \& Lambe, 2017). According to the 'hierarchy of media effects' model, for instance, perceptions and cognitions are more sensitive to media influence than attitudes or behaviors (McCombs et al., 2012). While classic theories of media effects such as agenda setting, cultivation and framing focus on societal perceptions and issue interpretations, today's discussions about fake news, social media and misperceptions reflect a continuous interest in the relationship between mediated communication and the pictures in our heads of the world outside. Since public perceptions of societal problems - their urgency, character, causes and consequences - matter for attributions of responsibility and political accountability, understanding their origins has been vital for public opinion research.

This chapter focuses specifically on how the (news) media influence perceptions of societal problems. This fundamental research question is addressed and reviewed in three ways. First, to better understand the context and contingencies of media effects on societal perceptions specifically, the outcome variable is related to the broader literature on sociotropic beliefs and cognitive schema theory. Second, classic theories of media effects focusing on societal perceptions are reviewed. The relevance and viability of these theories are discussed in light of the dramatic media environmental transformations of the last two decades. Third, a model of conditional media effects on sociotropic beliefs in contemporary high-choice media environments is proposed and discussed. The chapter concludes with some suggestions for future research on media effects on sociotropic beliefs. 


\section{Schema theory and the origins of sociotropic beliefs}

The pictures in our heads of the world outside are embedded within our cognitive systems. These mental structures help to effectively organize, process and interpret an otherwise chaotic stream of stimuli. According to schema theory, people's knowledge about issues, events, persons, etc. is stored in long-term memory as relatively stable mental models consisting of concepts, attributes, and relations between attributes (Fiske \& Taylor, 2017; Matthes, 2008). Schemas vary in levels of abstraction, development and detail. Citizens who are experts on certain domains posses well-developed schemas in those areas, with large stores of highly integrated and organized information - while others may have no specific domain-relevant schemas at all. Level of abstraction refers to the generality or applicability of a schema to a wider set of instances and situations. While some beliefs focus on impressions of single persons or events, others are more abstract, applying to larger categories and entities. The relationship between perceptions of specific instances, on the one hand, and broader patterns on the other hand, is critical for understanding the political significance of belief formation.

The idea that beliefs are composed of objects, attributes and relations reflects a common psychological understanding and fits well with established theories of media effects. Conceptually, beliefs are 'mental constructions about the probability that an object or event is associated with a given attribute' (Potter, 2012: 141). The concept of sociotropic beliefs refers to perceptions about societal matters (collective rather than personal experiences). The distinction between sociotropic and egotropic beliefs is widely used in research on economic voting, but is applicable to most other domains where citizens form perceptions about personal and societal level experiences. In terms of public opinion formation, sociotropic beliefs are particularly influential for attitude formation and government approval (Lewis-Beck \& Stegmaier, 2007; Mutz, 1998).

Figure 28.1 illustrates how preexisting cognitive schemas condition media effects on sociotropic beliefs. Both (1) schema development and (2) schema abstraction matter in terms of understanding the room for media influence as well as the significance of these effects. Put simply,

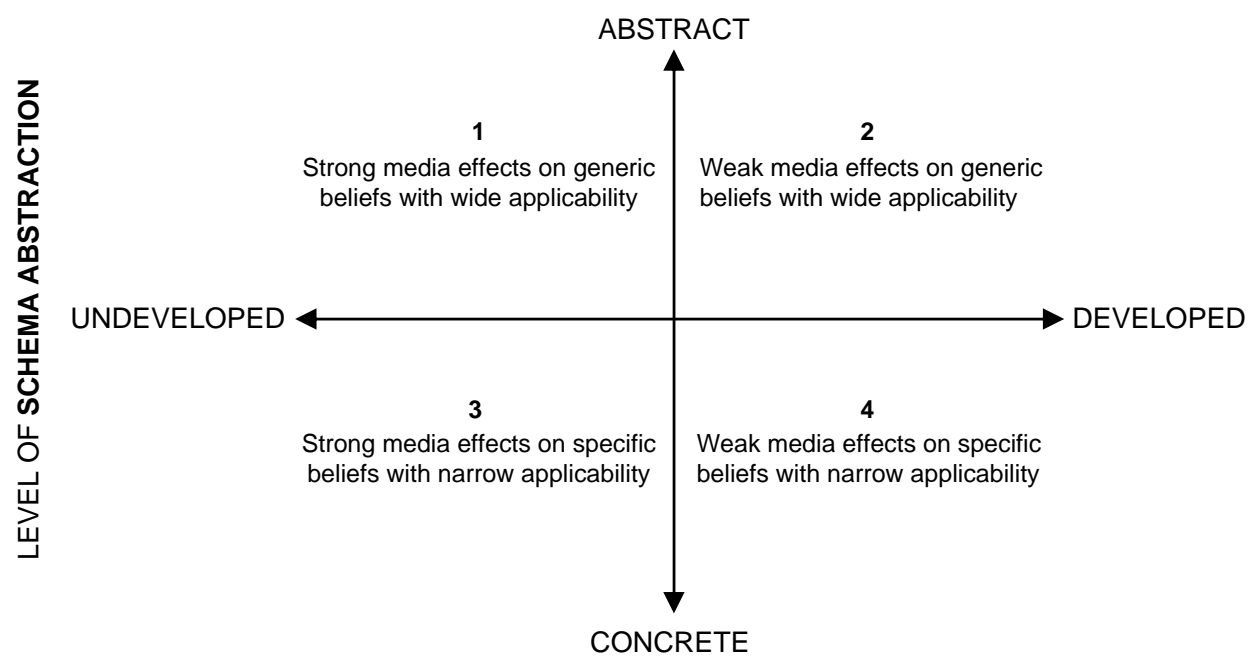

LEVEL OF SCHEMA DEVELOPMENT

Figure 28.1 The relationship between schema characteristics and media effects 
the less developed a certain schema, the larger is the potential immediate impact of exposure to media content on beliefs within that domain. More developed schemas are less likely to accommodate in response to media coverage. Furthermore, the more abstract a schema, the wider the applicability for subsequent assessments, judgments and attitudes. Very concrete schemas apply only to a narrow set of object-attribute beliefs and will therefore apply to a much smaller range of situations. The combination of schema development and abstraction gives rise to four media effect outcomes: (1) Strong media effects on generic beliefs with wide applicability; (2) weak media effects on generic beliefs with wide applicability; (3) strong media effects on specific beliefs with narrow applicability and (4) weak media effects on specific beliefs with narrow applicability.

Taken together, however, the public opinion literature emphasizes four different sources of sociotropic beliefs (Kumlin, 2004; Mutz, 1998). First, citizens may form perceptions of societal conditions through simple ideological or partisan rationalization. Such predispositions can potentially exert a significant impact on how citizens perceive the character, prevalence and causes of societal problems (Bisgaard, 2015; Taber \& Lodge, 2006). Whenever political polarization is strong, elite cues salient and social identities crystalized, such rationalization is expected to be of greater importance for citizens' perceptions of societal problems. A second potential source of sociotropic perceptions is direct personal experiences. Relying on personal experience entails a specific form of generalization or extrapolation from personal-level to societal-level judgments. Given the immediate accessibility and tangibility of personal experiences - often with significant implications for people's everyday lives - such experiences have the potential to have strong impact on societal-level perceptions. The extent to which personal experiences color perceptions of societal developments is highly debated however, as shown by research on perceptions of issues such as crime, the national economy and the environment (Egan \& Mullin, 2012; Kinder \& Kiewiet, 1981; Tyler \& Cook, 1984). At the same time, people may be more likely to draw upon personal experience when few other sources of information are available (Adoni \& Mane, 1984; Ball-Rokeach, 2010). Aside from partisan rationalization and personal experience, a third possible source is interpersonal communication. Talking to other people friends, family and colleagues - about political and societal matters is not only a way of sharing information, but also a setting where perceptions of reality are socially negotiated, validated and constructed (Eveland, 2004; Gamson, 1992). In that regard, everyday talk within social networks provides opportunities to learn about the experiences of significant others, but these networks also serve an important filtering function through which particular claims and messages are compared to test whether these beliefs are acceptable (De Vreese \& Boomgaarden, 2006; Schmitt-Beck, 2003). Finally, the fourth source of sociotropic perceptions emphasized in the literature is media coverage (Mutz, 1998). As a window to the world outside, the mass media are typically considered vital when it comes to judgments of societal-level developments. Not least the enormous literature on media effects has revealed the importance of media coverage in shaping perceptions of societal problems in situations when citizens lack alternative sources of information (Iyengar \& Kinder, 1987; McCombs, 2014; Mutz, 1998).

\section{Theories of media effects on sociotropic beliefs}

Three classic theories of media effects have been particularly influential and important for understanding sociotropic belief formation: agenda setting, cultivation and framing. Although their historical roots and theoretical emphases differ, they share a general focus on how media and media use influence perceptions and issue interpretations. Their relevance in today's fragmented high-choice media environment is nowadays frequently questioned - a question which will be discussed following a brief review of the classic theories. 


\section{Agenda setting effects}

Without doubt, agenda setting has been one of the most prominent theories in the field of mass communication since its original formulation in the early 1970s (McCombs, 2014; Shehata \& Strömbäck, 2013). The basic argument - tested in a large number of studies across the world holds that the mass media set the public agenda by influencing citizens' perceptions of issue importance. By focusing attention on specific societal issues, the news media provide cues regarding what societal problems deserve attention. Agenda setting is typically explained in terms of salience transfer from the media to the public, driven by an accessibility mechanism: perceptions about the importance of societal problems originate from top-of-mind considerations (Iyengar \& Kinder, 1987). As such, agenda setting should be seen as a low-cognitiveeffort effect.

Apart from influencing perceptions of societal problems, second-level agenda setting builds on the distinction between objects (first level) and attributes (second level). These studies extend the notion of perceptions of issue importance to also analyze what attributes (characteristics) people relate to these issues - that is, what aspects they have in mind when thinking about those issues (McCombs, 2014). Attribute agenda setting has also been studied at the actor level, looking at how media portrayals of political candidates influence public perceptions of those politicians (McCombs et al., 2000). These two levels of agenda setting are often summarized by noting that the news media are influential both in telling people both what to think about (object) as well as how to think about it (attribute). More recently, however, a third level of agenda setting has been proposed. According to the network agenda setting model, entire networks of interrelationships between objects and attributes are assumed to be influenced by broader patterns of news coverage - not only by the salience of single objects and attributes in the media ( $\mathrm{Vu}$ et al., 2014).

Agenda setting effects are however not universal within the population. Key concepts like issue obtrusiveness and need for orientation have been proposed to emphasize that media effects vary across issue domains and between citizens.

\section{Cultivation effects}

While agenda setting focuses explicitly on the news media, cultivation theory developed to explain broader cultural influences of television in particular (Gerbner, 1969). Cultivation is closely tied to the so-called 'mean-world syndrome' hypothesis: the idea that a consistent, regular and pervasive flow of violent crime narratives transmitted through television, influence viewers' sociotropic beliefs concerning crime (Morgan \& Shanahan, 2010; Perse \& Lambe, 2017). Both perceptions about the prevalence of violent crimes in society as well as fear of being a victim of crime are assumed to depend on the frequency of exposure to violence on television.

Cultivation theory and research has a number of distinct characteristics. First, cultivation effects are theorized as long-term influences. Rather than immediate short-term responses to specific content elements, people are assumed to be 'cultivated' through a consonant, repetitive and a stable system of dominant messages - resulting in cumulative reinforcement effects over time (Morgan, 2009; Potter, 2014). Second, most cultivation research has focused on the relationship between television viewing and crime perceptions. By distinguishing light from heavy viewers, studies analyze how people's perceptions deviate from real-world indicators as well as the 'television world'. Although crime has been the dominant focus, cultivation has also been analyzed in relation to other topics (Morgan et al., 2012). Third, while overall television viewing has been at the heart of cultivation research, the field has also developed towards 
genre-specific cultivation effects. This development reflects as a shift away from the original idea of content homogeneity across television channels and shows, towards content differentiation and audience selectivity. Fourth, the distinction between first-order and second-order cultivation effects correspond to how television influence societal perceptions (estimates of event frequencies and probabilities) on the one hand, and evaluations (attitudes or values) on the other hand. Psychological accounts of cultivation suggest that these two outcomes are driven by distinct mechanisms of memory-based (first-order) and online (second-order) information processing (Shrum \& Lee, 2012).

\section{Framing effects}

Compared to agenda setting and cultivation, the framing concept has roots in a more diverse literature (Entman, 1993; Scheufele, 2000). Conceptual definitions and analytical approaches have varied between cultural, sociological and psychological accounts of framing. As a theory of media effects, framing is sometimes compared to attribute agenda setting in its focus on how issues, events and actors are covered by the media. On the other hand, there are important differences as well.

While most framing effects studies focus on political attitudes, the primary outcome variable in framing is issue interpretation, that is, how citizens make sense of an issue, in terms of 'the presence, weight, and importance of considerations' (Matthes \& Schemer, 2012: 321). This distinguishes framing from persuasion. A classic example from the literature is the framing of a $\mathrm{Ku}$ Klux Klan rally as a matter of freedom of speech versus a disruption of public order: two competing frames related to different issue interpretations (Nelson et al., 1997). Framing effects occur when frames in communication, such as from the news media, influence citizens' frames in thought. In the words of Chong and Druckman (2007), framing 'refers to the process by which people develop a particular conceptualization of an issue or reorient their thinking about an issue' (p. 104). Thus, framing theory ultimately deals with citizens' sociotropic beliefs.

A range of generic frames used by the news media influence how people think about societal issues. For instance, research has identified attributions of responsibility, human interest, conflict, morality and economic consequences as distinct news frames that apply to various societal issues (Semetko \& Valkenburg, 2000). In addition, various issue-specific frames originating from political actors and public discourse, suggest competing problem definitions, causal attributions and treatment recommendations for particular policy issues (Entman et al., 2018). Empirical studies, mostly based on experiments, show that framing matters in this regard. While citizens tend to accept the dominant frames they are exposed to, studies also suggest that in the presence of competing frames, people accept and reject frames based on their resonance with personal predispositions. Thus, whether the news media report in a one-sided manner or provide competing frames, matter a great deal for public belief dynamics.

Research on agenda setting, cultivation and framing effects show that media matter when it comes to shaping beliefs about societal problems. A review of this literature from a sociotropic belief formation perspective, raises a few issues worth highlighting.

First, empirical studies of these classic theories vary greatly in terms of research design. Both agenda setting and cultivation research typically relies on observational survey data, while evidence of framing effects depend heavily on short-term experiments. Although aggregatelevel time-series data are not uncommon in studies of agenda-setting, cultivation research has 
been heavily criticized for lack of appropriate longitudinal designs (Potter, 2014). Given their distinct theoretical and conceptual focus, agenda setting, cultivation and framing studies also employ different measures of main dependent, independent and moderator variables.

Second, given the multiple sources of sociotropic beliefs outlined above, it is striking that relatively few studies put media effects in context. While there is broad consensus that media effects are conditional in nature (Lecheler \& de Vreese, 2018; McCombs, 2014; Valkenburg \& Peter, 2013), the sociotropic belief formation literature provides a comprehensive framework for analyzing the conditionality of media effects as dependent upon (1) ideological or partisan predispositions, (2) direct personal experiences as well as (3) communication within social networks. Although each of these moderators are theorized - and sometimes tested individually - there are significant empirical gaps in terms of a comprehensive understanding of media effects on sociotropic beliefs.

Third, despite theoretical claims that the most important effects of the news media may be long-term in nature, we currently know very little about long-term media effects on sociotropic beliefs (Perse \& Lambe, 2017; Tewksbury \& Scheufele, 2009). As noted by Koch and Arendt (2017): 'considering the amount of research that has been conducted on media effects, it is astonishing how little is known about the cumulation and duration of these effects' (p. 8). This has of course to do with research designs, which tend to be relatively short-term in nature, but is also a matter of theoretical clarification concerning what distinguishes long- from shortterm effects. Media effects on initial belief formation, belief maintenance and reinforcement, as well as various forms of belief moderation, polarization and conversion, cannot be reduced to questions about the duration of instantaneous belief changes. Without conceptual precision and appropriate research designs, some of these most important influences may remain largely invisible (Shehata et al., 2021).

Finally, these classic theories of media effects were developed in a very different era. Media environments and technologies have changed dramatically since then, leading to questions about the relevance of these theories for understanding belief dynamics in contemporary societies.

\section{Media effects in a changing media environment}

One of the most important changes relates to the number of choices citizens have in selecting media content. Beginning in the 1980s and accelerating drastically in the last two decades, the supply of content and content providers - in terms of television and radio channels, magazines and, not least, various online sources - has exploded. The gradual shift from a low-choice to a high-choice media environment allows people to personalize their media diets, selecting and avoiding content at the genre, ideological, channel, and outlet level. These expanding choice opportunities are likely to increase the role of personal motivations and resources as predictors of content selectivity (Prior, 2007; Strömbäck et al., 2013) - basically leading to audience fragmentation and polarization. These trends are further amplified by personalization algorithms governing various social media platforms. Algorithms that interact with active news choices may well serve citizens with news that reinforce and polarize along political and partisan lines although the extent to which this is the case is unclear (Zuiderveen Borgesius et al., 2016). The main implication for media effects theory, as noted by Chaffee and Metzger (2001) already 20 years ago, is that fewer people are exposed to the same media content (see also Bennett \& Iyengar, 2008; Cacciatore et al., 2016; Holbert et al., 2010 for more recent discussion about the relevance of classic media effects). 
Thus, trends towards greater opportunities for media choice has tilted research interest in favor of selective exposure theory (Bennett \& Iyengar, 2008; Stroud, 2011): the tendency of people to prefer and select content that match their already held beliefs. Again however, the extent to which people engage in selective exposure is highly contested and may vary depending on multiple contextual, situational and personal factors (Holbert et al., 2010; Stroud, 2011). But rather than concluding that media effects are no longer relevant, the contingencies of such effects have changed. While broad aggregate-level influences are becoming less likely, effects at the individual- or subgroup-level are still highly possible (Holbert et al., 2010; Semetko \& Valkenburg, 2000). Similarly, the fact that belief maintenance and reinforcement are becoming more common in a media environment characterized by increasing choice opportunities, underscores the changing - rather than diminishing - nature of media effects.

This is the main argument behind the Reinforcing Spirals Model (RSM) of media effects (Slater, 2007, 2015). RSM builds explicitly on the notion of media selectivity and media effects as an ongoing reciprocal spiral of influence. Beliefs that are tied to social and political identities - lifestyle, religion, politics - are particularly likely to influence content choice, which in turn contributes to the maintenance and reinforcement of identity-relevant beliefs and attitudes. In that sense, the RSM provides a theoretical framework for understanding selective and conditional media effects in contemporary democracies.

To summarize this brief review of media effects on sociotropic beliefs, Figure 28.2 presents a model of the main concepts and relationships at work. To begin with, sociotropic beliefs are assumed to be directly influenced by ideological rationalization and personal experiences $(\mathbf{J})$, interpersonal communication (I) and news media usage (A). Looking more closely at media effects $(\mathbf{A})$, these are conditioned by factors at the content level $(\mathbf{B})$, individual level $(\mathbf{C})$ and social network level (D). That is, the effects of news exposure depend on what issues, issue attributes and issue frames that are salient in news coverage. But these effects are also conditioned by citizens' personal experiences and political ideologies - as well as how they talk or discuss specific societal problems with family, friends and other people. The basic argument

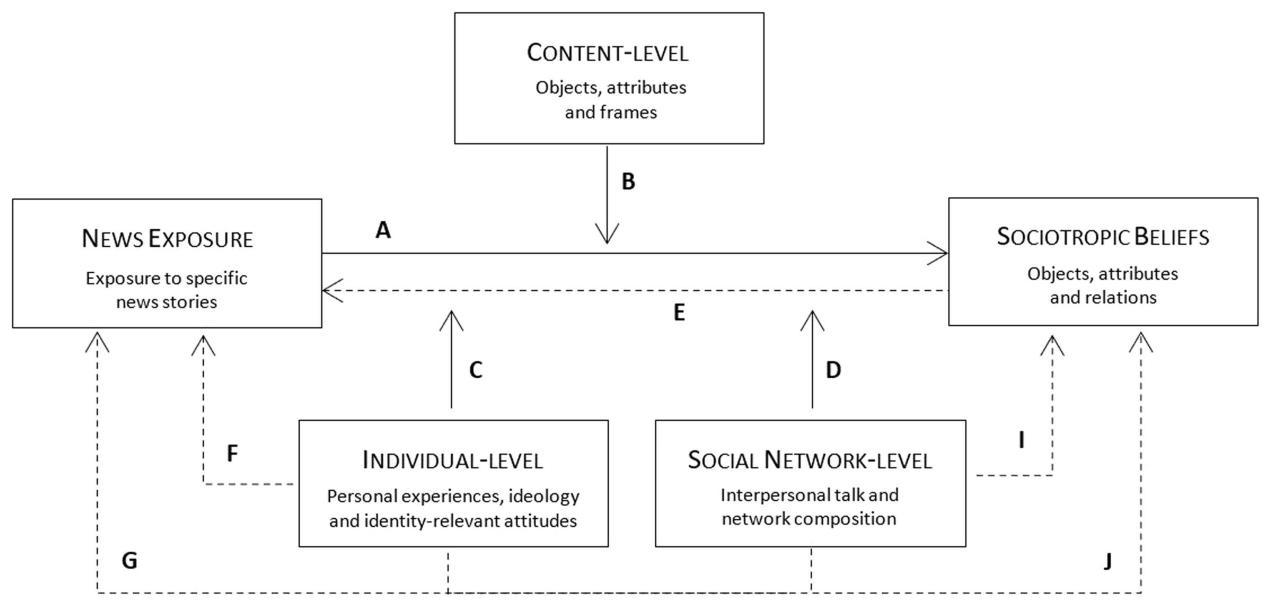

Figure 28.2 A model of media effects on sociotropic beliefs 
suggests that news coverage that resonates with experience, ideology and social network conversations, has a higher likelihood of being accepted by media consumers.

In addition, the model also accounts for media choice and selective exposure in various ways. News exposure is in itself driven by individual $(\mathbf{F})$ and social network $(\mathbf{G})$ level factors. What media content people actively seek-out or inadvertently stumble upon, depend on their personal motivations and social environment. The dynamic and mutually reinforcing influences emphasized by the RSM is captured by the feedback loop from sociotropic beliefs to news exposure $(\mathbf{E})$.

\section{Summary and conclusion}

This chapter has reviewed research on media effects on sociotropic beliefs. After anchoring beliefs in cognitive schema theory, arguing that the significance of media effects depends on preexisting schema characteristics, research on three classic theories of media effects were discussed: agenda setting, cultivation and framing. In light of the tremendous media environmental changes that have taken place across Western democracies, the chapter also discussed recent criticism towards media effects research. Rather than abandoning classic theories entirely, it was argued that greater sensitivity to the conditionalities of media effects - including various content selection processes - would strengthen future research.

Based on the review presented here as well as the proposed model of sociotropic belief formation, three areas deserve particular attention in future research. First, a more comprehensive and integrated approach is needed to better understand the conditionality of media effects. Sociotropic beliefs ultimately depend on a combination of ideological rationalization, personal experiences, social networks and mediated communication. As such, future research would gain from more ambitious analyses of the interactions between these various factors. Second, adding to the conditional effects approach, studies should account for different selection mechanisms to better understand media effects in today's fragmented communication environments. Incorporating both individual-level and social network-level factors behind news exposure provides an important avenue for future research on sociotropic belief formation. Finally, moving from short-term to long-term effect dynamics opens for a greater variety of media effects that remain largely invisible using the most commonly employed research designs. The news medias' influence on initial belief formation, gradual belief maintenance and reinforcement, as well as various forms of belief conversion, becomes evident only when citizens are studied over longer periods of time.

\section{Acknowledgment}

This project has received funding from the European Research Council (ERC) under the European Union's Horizon 2020 research and innovation program (grant agreement No 804662). The project was also supported by a grant from the Swedish Research Council (VR 2016-02262).

\section{References}

Adoni, H. \& Mane, S. (1984). 'Media and the Social Construction of Reality: Toward an Integration of Theory and Research'. Communication Research, 11(3), pp. 323-340.

Ball-Rokeach, S.J. (2010). 'Media System Dependency Theory'. In: Donsbach, W. (Ed.), The International Encyclopedia of Communication. Oxford: Blackwell. 
Bennett, W. L. \& Iyengar, S. (2008). 'A New Era of Minimal Effects? The Changing Foundations of Political Communication'. Journal of Communication, 58(4), pp. 707-731.

Bisgaard, M. (2015). 'Bias Will Find a Way: Economic Perceptions, Attributions of Blame, and PartisanMotivated Reasoning during Crisis'. The Journal of Politics, 77(3), pp. 849-860.

Cacciatore, M. A., Scheufele, D. A. \& Iyengar, S. (2016). 'The End of Framing as We Know It ... and the Future of Media Effects'. Mass Communication and Society, 19(1), pp. 7-23, DOI: 10.1080/15205436.2 015.1068811.

Chaffee, S. \& Metzger, M. (2001). 'The End of Mass Communication?' Mass Communication and Society, 4(4), pp. 365-379.

Chong, D. \& Druckman, J. (2007). 'Framing Theory.' Annual Review of Political Science, 10, pp. 103-126.

De Vreese, C. \& Boomgaarden, H. (2006). 'Media Message Flows and Interpersonal Communication: The Conditional Nature of Effects on Public Opinion.' Communication Research, 33(1), pp. 19-37.

Egan, P. J. \& Mullin, M. (2012). 'Turning Personal Experience into Political Attitudes: The Effect of Local Weather on Americans' Perceptions about Global Warming'. The Journal of Politics, 74(3), pp. 796-809, DOI: 10.1017/s0022381612000448.

Entman, R. (1993). 'Framing: Toward Clarification of a Fractured Paradigm'. Journal of Communication, 43, pp. 51-58.

Eveland, W.P. (2004). 'The Effect of Political Discussion in Producing Informed Citizens: The Roles of Information, Motivation, and Elaboration'. Political Communication, 21(2), pp. 177-193.

Gamson, W. (1992). Talking Politics. Cambridge: Cambridge University Press.

Fiske, S. \& Taylor, S. (2017). Social Cognition: From Brains to Culture. Thousand Oaks: Sage.

Gerbner, G. (1969). 'Toward "Cultural Indicators": The Analysis of Mass Mediated Message Systems'. Communication Review, 17, pp. 137-148.

Holbert, R., Garrett, R.K. \& Gleason, L. (2010). 'A New Era of Minimal Effects? A Response to Bennett and Iyengar'. Journal of Communication, 60(1), pp. 15-34.

Iyengar, S. \& Kinder, D. (1987). News That Matters: Television and American Opinion. Chicago: The University of Chicago Press.

Lewis-Beck, M. \& Stegmaier, M. (2007). 'Economic Models of Voting'. In: Dalton, R. \& Klingemann, H-D. (Eds.), The Oxford Handbook of Political Behavior. Oxford: Oxford University Press, pp. 518-537.

Kinder, D. \& Kiewiet, R. (1981). 'Sociotropic Politics: The American Case'. British Journal of Political Science, 11(2), pp. 129-161.

Koch, T. \& Arendt, F. (2017). 'Media Effects: Cumulation and Duration'. The International Encyclopedia of Communication. Oxford: Blackwell, pp. 1-11.

Kumlin, S. (2004). The Personal and the Political: How Personal Welfare State Experiences Affect Political Trust and Ideology. New York: Palgrave.

Lecheler, S. \& de Vreese, C. (2018). News Framing Effects. New York: Routledge.

Lippmann, W. (1922/1997). Public Opinion. New York: Free Press Paperbacks.

Matthes, J. (2008). 'Schemas and Media Effects'. In: Donsbach, W. (Ed.), The International Encyclopedia of Communication. Oxford: Blackwell, pp. 4502-4508.

Matthes, J. \& Schemer, C. (2012). 'Diachronic Framing Effects in Competitive Opinion Environments'. Political Communication, 29(3), pp. 319-339.

McCombs, M. (2014). Setting the Agenda: The Mass Media and Public Opinion. Cambridge, England: Polity Press.

McCombs, M., Holbert, R.L., Kiousis, S. \& Wanta, W. (2012). The News and Public Opinion: Media Effects on Civic Life. Malden, MA: Polity.

McCombs, M., Lopez-Escobar, E. \& Llamas, J.P. (2000). 'Setting the Agenda of Attributes in the 1996 Spanish General Election'. Journal of Communication, 50, pp. 77-92.

Morgan, M. (2009). 'Cultivation Analysis and Media Effects'. In: Nabi, R. L. \& Oliver, M. O. (Eds.), The Sage Handbook of Media Processes and Effects. Los Angeles, CA: Sage, pp. 69-82.

Morgan, M., \& Shanahan, J. (2010). 'The State of Cultivation'. Journal of Broadcasting \& Electronic Media, 54(2), pp. 337-355.

Morgan, M., Shanahan, J. \& Signorielli, N. (2012). Living With Television Now: Advances in Cultivation Theory and Research. New York: Peter Lang.

Mutz, D. (1998). Impersonal Influence. How Perceptions of Mass Collectives Influence Political Attitudes. Cambridge: Cambridge University Press.

Nelson, T.E., Clawson, R.A. \& Oxley, Z.M. (1997). 'Media Framing of Civil Liberties Conflict and Its Effect on Tolerance'. American Political Science Review, 91, pp. 567-583. 
Perse, E. \& Lambe, J. (2017). Media Effects and Society. New York: Routledge.

Potter, J. (2014). 'A Critical Analysis of Cultivation Theory.' Journal of Communication, 64(6), pp. 1015-1036.

Potter, J. (2012). Media Effects. Thousand Oaks: SAGE.

Prior, M. (2007). Post-broadcast Democracy. How Media Choice Increases Inequality in Political Involvement and Polarizes Elections. New York: Cambridge University Press.

Scheufele, D. (2000). 'Agenda-setting, Priming, and Framing Revisited: Another Look at Cognitive Effects of Political Communication'. Mass Communication and Society, 3(2-3), pp. 297-316.

Schmitt-Beck, R. (2003). 'Mass Communication, Personal Communication and Vote Choice: The Filter Hypothesis of Media Influence in Comparative Perspective'. British Journal of Political Science, 33(2), pp. 233-259.

Semetko, H. \& Valkenburg, P. (2000). 'Framing European Politics: A Content Analysis of Press and Television News'. Journal of Communication, 50, pp. 93-109.

Shehata, A. Andersson, D., Glogger, I. Hopmann, D.N. Andersen, K., Kruikemeier, S. \& Johansson, J. (2021). 'Conceptualizing long-term media effects on societal beliefs'. Annals of the International Communication Association, 45(1), pp. 75-93. https://doi.org/10.1080/23808985.2021.1921610

Shehata, A., \& Strömbäck, J. (2013). 'Not a New Era of Minimal Effects: A Study of the Dynamics of Agenda Setting at the Aggregate and Individual Level'. The International Journal of Press/Politics, 18, pp. 234-255.

Shrum. L. \& Lee, J. (2012). 'Multiple Processes Underlying Cultivation Effects: How Cultivation Works Depends on the Type of Beliefs Being Cultivated'. In: Morgan, M., Shanahan, J. \& Signorielly, N. (Eds.), Living With Television Now. New York: Peter Lang, pp. 146-167.

Slater, M. (2015). 'Reinforcing Spirals Model: Conceptualizing the Relationship Between Media Content Exposure and the Development and Maintenance of Attitudes'. Media Psychology, 18(3), pp. 370-395.

Slater, M. (2007). 'Reinforcing Spirals: The Mutual Influence of Media Selectivity and Media Effects and Their Impact on Individual Behavior and Social Identity'. Communication Theory, 17(3), pp. 281-303.

Strömbäck, J., Djerf-Pierre, M. \& Shehata, A. (2013). 'The Dynamics of Political Interest and News Media Consumption: A Longitudinal Perspective'. International Journal of Public Opinion Research, 25(4), pp. 414-435.

Stroud, N. J. (2011). Niche News: The Politics of News Choice. New York, NY: Oxford University Press.

Taber, C. \& Lodge, M. (2006). 'Motivated Skepticism in the Evaluation of Political Beliefs'. American Journal of Political Science, 50(3), pp. 755-769.

Tewksbury, D. \& Scheufele, D. (2009). 'News Framing Theory and Research'. In: Bryant, J. \& Oliver, M.B. (Eds.), Media Effects: Advances in Theory and Research. New York, NY: Routledge, pp. 17-33.

Tyler, T.R. \& Cook, F.L. (1984). 'The Mass Media and Judgments of Risk: Distinguishing Impact on Personal and Societal Level Judgments'. Journal of Personality and Social Psychology, 47(4), pp. 693-708.

Valkenburg, P. \& Peter, J. (2013). 'The Differential Susceptibility to Media Effects Model'. Journal of Communication, 63(2), pp. 221-243.

Vu, H., Guo, L. \& McCombs, M. (2014). 'Exploring “the World Outside and the Pictures in Our Heads": A Network Agenda-setting Study'. Journalism \& Mass Communication Quarterly, 91, pp. 669-686.

Zuiderveen Borgesius, F., Trilling, D., Möller, J., Bodó, B., de Vreese, C. \& Helberger, N. (2016). 'Should We Worry About Filter Bubbles?' Internet Policy Review, 5(1), pp. 1-16, DOI: 10.14763/201 6.1.401. 